\title{
Correction to: User interest community detection on social media using collaborative filtering
}

\author{
Liang Jiang ${ }^{1,3} \cdot$ Leilei Shi ${ }^{1} \cdot$ Lu Liu $^{2} \cdot$ Jingjing $\mathrm{Yao}^{4} \cdot$ Moses Edward $\mathrm{Ali}^{2}$
}

Published online: 12 November 2021

(C) Springer Science+Business Media, LLC, part of Springer Nature 2021

\section{Correction to:}

Wireless Networks (2019) 25:4443 https://doi.org/10.1007/s11276-018-01913-4

The original version of this article unfortunately contained a mistake in the author group. The fifth author, Muhammad Ali Yousuf, has changed his name to Moses Edward Ali due to religious conversion. The correct author group is published with this correction.

Publisher's Note Springer Nature remains neutral with regard to jurisdictional claims in published maps and institutional affiliations.

The original article can be found online at https:// doi.org/10.1007/s11276-018-01913-4.

Lu Liu

1.liu@derby.ac.uk

1 School of Computer Science and Telecommunication Engineering, Jiangsu University, Zhenjiang, China

2 Department of Computing and Mathematics, University of Derby, Derby, UK

3 Jingjiang College of Jiangsu University, Zhenjiang, China

4 School of Economy and Finance, Jiangsu University, Zhenjiang, China 